\title{
Protein Tyrosine Phosphatase- $\mu$ Differentially Regulates Neurite Outgrowth of Nasal and Temporal Neurons in the Retina
}

\author{
Susan M. Burden-Gulley, Sonya E. Ensslen, and Susann M. Brady-Kalnay \\ Department of Molecular Biology and Microbiology and Department of Neurosciences, School of Medicine, Case \\ Western Reserve University, Cleveland, Ohio 44106-4960
}

Cell adhesion molecules play an important role in the development of the visual system. The receptor-type protein tyrosine phosphatase, $\mathrm{PTP} \mu$, is a cell adhesion molecule that mediates cell aggregation and may signal in response to adhesion. PTP $\mu$ is expressed in the chick retina during development and promotes neurite outgrowth from retinal ganglion cell (RGC) axons in vitro (Burden-Gulley and Brady-Kalnay, 1999). The axons of RGC neurons form the optic nerve, which is the sole output from the retina to the optic tectum in the chick. In this study, we observed that PTP $\mu$ expression in RGC axons occurs as a step gradient, with temporal axons expressing the highest level of $\mathrm{PTP} \mu$. РTP $\mu$ expression in the optic tectum occurred as a smooth descending gradient from anterior to posterior regions during development. Because temporal RGC axons innervate anterior tectal regions, $\mathrm{PTP} \mu$ may regulate the formation of topographic projections to the tectum. In agreement with this hypothesis, a differential response of RGC neurites to a PTP $\mu$ substrate was also observed: RGCs of temporal retina were unable to extend neurites on $\mathrm{PTP} \mu$ compared with neurites of nasal retina. When given a choice between $\mathrm{PTP} \mu$ and a second substrate, the growth cones of temporal neurites clustered at the PTP $\mu$ border and stalled, thus avoiding additional growth on the PTP $\mu$ substrate. In contrast, PTP $\mu$ was permissive for growth of nasal neurites. Finally, application of soluble PTP $\mu$ to retinal cultures resulted in the collapse of temporal but not nasal growth cones. Therefore, PTP $\mu$ may specifically signal to temporal RGC axons to cease their forward growth after reaching the anterior tectum, thus allowing for subsequent innervation of deeper tectal layers.

Key words: neurite outgrowth; protein tyrosine phosphatase; cell adhesion; retina; tectum; pathfinding
Studies on axon pathfinding have revealed that a multitude of factors, working in concert, are required for the guidance of axons to their appropriate targets during development (Goodman, 1996; Tessier-Lavigne and Goodman, 1996). The chick visual system has been used frequently for the study of axon pathfinding because it is readily accessible during development and consists of a limited number of components, including the retina, optic tectum, and a few thalamic nuclei (Thanos and Mey, 2001). Axons from retinal ganglion cells (RGCs) form the optic fiber layer (OFL) in the retina and are the sole output from the neural retina for communication with the optic tectum, the main visual center in the chick brain. Projection of RGC axons to the contralateral optic tectum occurs in a highly topographic manner, thus preserving relationships between neighboring RGC axons (Rager, 1980). To explain this stereotypical projection pattern, Sperry (1963) formulated the chemoaffinity hypothesis, in which gradients of a limited number of cytochemical labels within the

Received Aug. 31, 2001; revised Dec. 6, 2001; accepted Jan. 28, 2002.

This study was supported by National Institutes of Health Grant 1RO1-EY12251 (S.B.K.). Additional support was provided by Visual Sciences Research Center Core Grant PO-EY11373 from the National Eye Institute. A number of individuals provided assistance with this study, and their efforts were greatly appreciated. These include Jullia Rosdahl [Case Western Reserve University (CWRU)], who assisted in developing the immunohistochemistry protocols, and Dr. Vance Lemmon (CWRU) for providing antibodies and helpful discussion throughout the course of this study. In addition, we are grateful to Dr. William Crossland (Wayne State University School of Medicine, Detroit, MI) for providing valuable input during analysis of $\mathrm{PTP} \mu$ expression in the visual system and for critically reading this manuscript.

Correspondence should be addressed to Susann M. Brady-Kalnay, Department of Molecular Biology and Microbiology, Case Western Reserve University, 10900 Euclid Avenue, Cleveland, OH 44106-4960. E-mail: smb4@po.cwru.edu. Copyright (C) 2002 Society for Neuroscience $0270-6474 / 02 / 223615-13 \$ 15.00 / 0$ retina and tectum would allow ingrowing retinal axons to recognize their appropriate site of innervation.

In accordance with the chemoaffinity hypothesis, the Eph receptor tyrosine kinase A3 and its ephrin ligands A2 and A5 occur in gradients within the retina and tectum, respectively (Cheng et al., 1995; Drescher et al., 1995). Recent evidence has indicated that these molecules actively regulate retinotectal pathfinding (Nakamoto et al., 1996; Feldheim et al., 2000). Given that ephrin binding to its receptor activates tyrosine kinase activity (Davis et al., 1994; Holland et al., 1996), tyrosine phosphorylation is predicted to be an important component of the inhibitory signal generated. Tyrosine phosphorylation is regulated by both kinases and phosphatases, yet the function of tyrosine phosphatases in retinotectal pathfinding has not been clearly defined.

Receptor-type protein tyrosine phosphatases (RPTPs) are enzymes that catalyze the dephosphorylation of tyrosine residues. RPTPs are intriguing proteins because they couple CAM-like extracellular domains with enzymatic activity, suggesting that they send signals directly in response to adhesion. Multiple RPTPs have been localized to the nervous system (Shock et al., 1995; Stoker et al., 1995b; Bodden and Bixby, 1996; Fuchs et al., 1998; Stoker and Dutta, 1998; Ledig et al., 1999b; Johnson and Holt, 2000), and a limited number of these have been demonstrated to play a role in axon guidance in Drosophila (Desai et al., 1996; Krueger et al., 1996; Garrity et al., 1999; Sun et al., 2000a, 2001). Several RPTPs are expressed in the developing visual system of chick (Stoker et al., 1995a; Burden-Gulley and BradyKalnay, 1999; Ledig et al., 1999b), and a subset of RPTPs are capable of promoting neurite outgrowth from retinal cells 
(Burden-Gulley and Brady-Kalnay, 1999; Ledig et al., 1999a), suggesting a potential role in retinotectal pathfinding.

This study investigates the RPTP- $\mu(\mathrm{PTP} \mu)$ and its role in retinotectal development. $\mathrm{PTP} \mu$ binds homophilically, such that РТР $\mu$ on the surface of one cell interacts with $\mathrm{PTP} \mu$ on the surface of an adjacent cell (Brady-Kalnay et al., 1993; Gebbink et al., 1993). Immunoblot analysis indicates that $\mathrm{PTP} \mu$ expression in the retina occurs shortly after the RGCs differentiate [embryonic day $4(\mathrm{E} 4)$ ] and is maintained throughout the developmental period when RGC axons are growing to and form connections with the optic tectum (Burden-Gulley and Brady-Kalnay, 1999). We have shown previously that at E8, the time of vigorous RGC pathfinding to the tectum, $\mathrm{PTP} \mu$ is expressed primarily by RGC axons and cell bodies in the chick retina (Burden-Gulley and Brady-Kalnay, 1999). Of significant interest, РТP $\mu$ promotes neurite outgrowth from RGCs when used as a substrate in vitro (Burden-Gulley and Brady-Kalnay, 1999).

In this study, we demonstrate that $\mathrm{PTP} \mu$ expression occurs in a gradient in both the retina and optic tectum. These results suggest that $\mathrm{PTP} \mu$ may play a role in the formation of topographic connections between RGC axons and the optic tectum. When $\mathrm{PTP} \mu$ is used as a substrate for neurite outgrowth from retinal explants, RGCs of ventral-temporal origin display a reduced ability to extend neurites on a $\mathrm{PTP} \mu$ substrate compared with RGCs of ventral-nasal origin. Culture of retinal explants on alternating lanes of $\mathrm{PTP} \mu$ and $\mathrm{N}$-cadherin substrates revealed that ventral-temporal neurites prefer to grow on $\mathrm{N}$-cadherin and stall on contact with $\mathrm{PTP} \mu$ lanes. In contrast, ventral-nasal neurites freely cross onto and remain on $\mathrm{PTP} \mu$ lanes. In addition, the application of soluble $\mathrm{PTP} \mu$ to retinal cultures resulted in the specific collapse of growth cones from temporal but not nasal retina. Together, these results suggest that $\mathrm{PTP} \mu$-mediated adhesion activates a signal that specifically regulates temporal RGC axons in vitro, corresponding to the cessation of forward growth and subsequent innervation of the anterior tectum in vivo.

\section{MATERIALS AND METHODS}

Culture of retinal explants. $\mathrm{PTP} \mu$ and $\mathrm{N}$-cadherin were purified from brain using previously described methods (Bixby and Zhang, 1990; Burden-Gulley and Brady-Kalnay, 1999). Laminin was obtained from Invitrogen (San Diego, CA). Retinal explants were cultured as described previously (Halfter et al., 1983; Drazba and Lemmon, 1990), except that in some cases, the retina was flattened on a filter and explants were cut in an orientation parallel to the optic fissure. The substrate lane assay was done using slight modifications of the Bonhoeffer method (Vielmetter et al., 1990). Briefly, tissue culture dishes were coated with nitrocellulose (Lagenaur and Lemmon, 1987) and dried, and the silicon lane matrix was applied to the dish surface. The first substrate was injected into the channels of the matrix, incubated for $10 \mathrm{~min}$, aspirated, and then replaced with a fresh aliquot of the same substrate for several cycles. All remaining binding sites within the lanes were blocked with bovine serum albumin (BSA; fraction V; Sigma, St. Louis, MO), and the lanes were rinsed with calcium/magnesium-free phosphate buffer (CMF). The matrix was removed, and the lanes were dried briefly. A small amount of Texas Red-conjugated BSA (Molecular Probes, Eugene, OR) was added to the second substrate to allow for substrate identification by fluorescence microscopy. The second substrate was spread across the lane area and incubated for $30 \mathrm{~min}$. The entire dish was blocked with BSA and then rinsed with RPMI-1640 medium (Invitrogen). Retinal explants were cultured in RPMI-1640, 10\% fetal bovine serum (Summit, Fort Collins, $\mathrm{CO}$ ), $2 \%$ chick serum (Sigma), and $2 \mathrm{~mm}$ L-glutamine-antibiotic-antimycotic (100 U penicillin, $0.1 \mathrm{mg} / \mathrm{ml}$ streptomycin, $0.25 \mu \mathrm{g} / \mathrm{ml}$ amphotericin B; Sigma). Lane assays were analyzed at $48 \mathrm{hr}$ after culture.

Quantification of neurite outgrowth. Neurite outgrowth from specific regions of the retina was analyzed using the Metamorph image analysis program (Universal Imaging, West Chester, PA) as described previously (Burden-Gulley and Brady-Kalnay, 1999). In short, the area of neurite outgrowth was outlined to define the region of interest, the neurites were highlighted using the threshold function, and the total number of highlighted pixels per region of interest was calculated. This method provided a means to compare density of outgrowth between specific retinal regions on each substrate. The neurite density measurements were analyzed by Fisher's protected least significant difference test (PLSD; Statview 4.51; Abacus Concepts, Inc., Calabasas, CA). The data from all like experiments were combined and plotted (Cricketgraph III; Computer Associates International, Inc., Islandia, NY).

Growth cone collapse assay. Retinal explants were cultured as described above on a laminin substrate for $22 \mathrm{hr}$. Explants were cut across the optic fissure so that both nasal and temporal retina was present in each explant. Only explants from ventral retina were used, because this corresponded with the region that was responsive to РTP $\mu$ in the lane assays. РTP $\mu$ and N-cadherin proteins were purified from brain (Bixby and Zhang, 1990; Burden-Gulley and Brady-Kalnay, 1999) and dialyzed into RPMI1640 medium (Invitrogen) overnight at $4^{\circ} \mathrm{C}$. The dialyzed proteins or RPMI medium was added to individual dishes with gentle mixing, and the dishes were returned to a $37^{\circ} \mathrm{C}$ incubator for $10 \mathrm{~min}$. The cells were then fixed and analyzed for growth cone collapse. Images of growth cones were acquired from nasal and temporal regions of each explant and scored for collapse. The total number of growth cones scored per treatment was 645 for RPMI, 657 for N-cadherin and 1114 for PTP $\mu$. Collapse was defined as a complete loss of lamellipodial veils, and the majority of cases also included the loss of all filopodia. Data from several experiments were combined ( $n=5$ for $\mathrm{PTP} \mu$ application; $n=3$ for $\mathrm{N}$-cadherin application; $n=3$ for RPMI application) and analyzed using Fisher's PLSD and Student's $t$ test (Statview 4.51; Abacus Concepts, Inc.) at a $99 \%$ confidence level. The data were plotted with Cricketgraph III (Computer Associates International, Inc.).

Immunoblot analysis. Tissue lysates were prepared by dissecting nasal retina from temporal retina or anterior tectum from posterior tectum at different developmental stages in cold CMF and transferring to cold lysis buffer (20 mm Tris, pH 7.6, 1\% Triton X-100, 1 mm benzamidine, $1 \mathrm{~mm}$ sodium orthovanadate, $0.1 \mathrm{~mm}$ ammonium molybdate, $0.2 \mathrm{~mm}$ phenyl arsine oxide, $0.3 \%$ protease inhibitor cocktail; P8340; Sigma). The tissue was disrupted using a Pro-200 homogenizer (ProScientific, Monroe, CT) and incubated on ice for $30 \mathrm{~min}$. The Triton-insoluble material was removed by centrifugation (14,000 rpm for $3 \mathrm{~min}$ in a microf uge), and the protein concentration of the supernatant was determined by the method of Bradford (1976). Equal amounts of protein were loaded per lane and separated by SDS-PAGE ( $6 \%$ gels). Proteins were transferred to nitrocellulose membrane (Schleicher and Schuell, Keene, NH) and immunoblotted as described previously using an antibody generated against РTP $\mu$ (SK18) (Brady-Kalnay et al., 1993; Brady-Kalnay and Tonks, 1994). To verify equal protein load per lane, the immunoblots were stripped and reprobed (Reblot Plus; Chemicon International, Temecula, CA) with a monoclonal antibody against vinculin (V9131; Sigma).

Immunohistochemistry. Retinas or brains were dissected in ice-cold CMF. Tissue was fixed by incubation in $4 \%$ paraformaldehyde in PEM buffer ( 80 mm PIPES, 5 mm EGTA, 1 mM $\mathrm{MgCl}_{2}$, $3 \%$ sucrose), $\mathrm{pH} 7.4$, at $4^{\circ} \mathrm{C}$ ( $2 \mathrm{hr}$ for retinas, $16 \mathrm{hr}$ for whole brains or heads), followed by copious PBS rinses. Tissue was cryopreserved by incubation in increasing concentrations of sucrose to $25 \%$ in PBS and then embedded in tissue freezing medium (Electron Microscopy Sciences, Fort Washington, PA). Sections were cut on a cryostat at $10 \mu \mathrm{m}$ intervals and stored at $-20^{\circ} \mathrm{C}$.

Sections were air-dried, rinsed with PBS, and then incubated in $0.3 \%$ $\mathrm{H}_{2} \mathrm{O}_{2}$ to inactivate endogenous peroxidases. Sections were blocked and permeabilized with $1 \%$ saponin $/ 1 \% \mathrm{BSA} / 1.5 \%$ horse serum/PBS and then incubated in primary antibody diluted in block buffer for 16-20 hr at $4^{\circ} \mathrm{C}$. Hybridoma culture supernatant was diluted $1: 10$, whereas ascites was diluted 1:1000. After PBS rinses, sections were incubated in biotinylated secondary antibody [Vectastain Elite avidin-biotin complex (ABC) kit; Vector Laboratories, Burlingame, CA] diluted in block buffer for $45 \mathrm{~min}$ at room temperature. Sections were rinsed and then incubated in $\mathrm{ABC}$ reagent in $0.5 \%$ saponin/PBS for $45 \mathrm{~min}$ at room temperature. After PBS rinses, sections were incubated with diaminobenzidine solution (Sigmafast DAB; Sigma) for 2-5 min and then rinsed with PBS. Sections were dehydrated through a graded ethanol series and then coverslipped using Clearium mounting medium (Surgipath Medical Industries, Richmond, IL). Sections were analyzed using a Nikon (Tokyo, Japan) TE 200 inverted microscope using bright-field optics. Images were captured with a SPOT RT digital camera and image acquisition software (Diagnostic Instruments, Inc., Sterling Heights, MI). 
To label cellular nuclei with 4',6-diamidino-2-phenylindole, dihydrochloride (DAPI) (Molecular Probes), sections were permeabilized and blocked with $1 \%$ saponin $/ 1 \%$ BSA/20\% goat serum/PBS for $30 \mathrm{~min}$ at room temperature and then incubated with $1 \mu \mathrm{g} / \mathrm{ml}$ DAPI in block buffer for $30 \mathrm{~min}$ at room temperature. Sections were rinsed with PBS and coverslipped using SlowFade Light mounting medium (Molecular Probes). Sections were analyzed using a Zeiss (Oberkochen, Germany) Axioplan-2 microscope equipped with fluorescence optics. Images were captured with a Hamamatsu (Bridgewater, NJ) C4742 cooled CCD camera using the QED image acquisition software (QED Imaging Inc., Pittsburgh, PA).

Quantification of $P T P \mu$ expression in immunohistochemically labeled tissue sections. Digitized images of labeled tissue sections were analyzed with MetaMorph image analysis software (Universal Imaging) using an adaptation of a previously described protocol (Lyckman et al., 2001). Images were normalized to 256 levels of gray, with white set to zero, so that higher gray values corresponded to a greater staining intensity. A region of interest was defined, and the average gray-level values within the defined region were calculated. For the retina measurements, the region of interest encompassed the full width of the retina. Multiple measurements were made in the nasal and temporal halves of the retina sections and in the fissure region where the ganglion cell axons coalesce to form the optic nerve. For the tectum, measurements were made using two distinct regions of interest. The first encompassed the entire width of the tectum, whereas the second region included only the stratum opticum (SO) and stratum griseum and fibrosum superficiale (SGFS) layers. Measurements were obtained from four distinct regions of the horizontal tectum sections: anterior, anterolateral, lateral, and posterior. Average gray-level values for each region were plotted using Cricketgraph III (Computer Associates International, Inc.).

\section{RESULTS}

\section{Expression of PTP $\boldsymbol{\mu}$ in the retina and optic chiasm}

CAMs are important in several steps of retinal development, including the formation of laminas, axon growth within the retina, axon fasciculation, and growth within the optic nerve (for review, see Mey and Thanos, 1992; Thanos and Mey, 2001). РТР $\mu$ is abundant in many parts of the CNS, including the retina (Gebbink et al., 1991; Brady-Kalnay et al., 1995; Brady-Kalnay, 1998; Ledig et al., 1999b). The fact that РTP $\mu$ promotes outgrowth of RGC neurites suggests a potential role in axon guidance. Because the only known ligand for $\mathrm{PTP} \mu$ binding is $\mathrm{PTP} \mu$, we examined $\mathrm{PTP} \mu$ expression in the retina and tectum at several developmental ages that correspond to the period when RGC axons grow to and form synapses in the optic tectum (Fig. 1). Lysates were made from nasal and temporal regions of the retina at different developmental ages, separated by SDS-PAGE, and immunoblotted for PTP $\mu$ (Fig. $1 A$ ). PTP $\mu$ expression increased during development (Fig. 1A) (Burden-Gulley and Brady-Kalnay, 1999). In addition, the full-length form of $\mathrm{PTP} \mu(\sim 200 \mathrm{kDa})$ increased in size during development, possibly because of glycosylation or alternative splicing (Fig. $1 A$ ). No difference in $\operatorname{PTP} \mu$ expression was detected in temporal retina lysates compared with nasal retina lysates at the developmental ages examined. Equal protein load per lane was verified by stripping the blot and probing it for vinculin (Fig. $1 A$ ). These results demonstrate that $\mathrm{PTP} \mu$ expression increases in the retina during development.

To gain a better understanding of $\mathrm{PTP} \mu$ expression in the developing retina, E8 retinas (stage 32 ) were sectioned and immunohistochemically labeled for $\operatorname{PTP} \mu$ (Fig. 2B). The ventral retina was sectioned across the optic fissure so that nasal and temporal retina were both present in each section. The control sections were labeled with an antibody against NgCAM (8D9) (Fig. $2 A$ ), a member of the L1 family of CAMs that is expressed by RGC axons (Lemmon and McCloon, 1986). RGC neurons differentiate in a central-to-peripheral wave (Halfter et al., 1985) and express $\mathrm{NgCAM}$ by $\mathrm{E} 4$ in the $\mathrm{OFL}$ of the inner retina

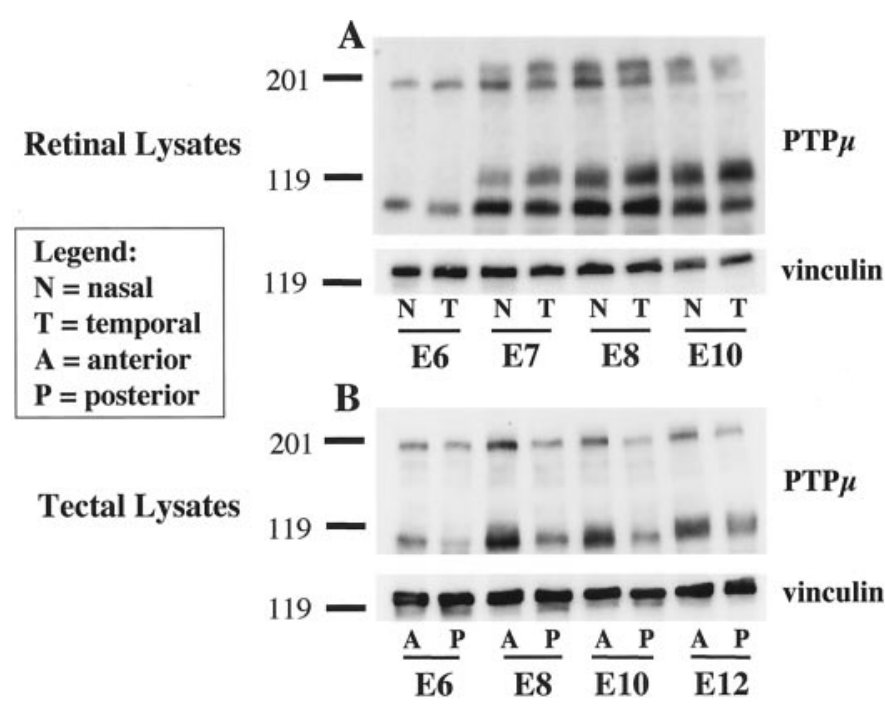

Figure 1. Immunoblot analysis of $\mathrm{PTP} \mu$ expression in the developing retina and optic tectum. Lysates from nasal or temporal retina $(A)$ and anterior or posterior tectum $(B)$ were made from E6 to E12 chicks. Lysates were separated by SDS-PAGE ( $6 \%$ gel), transferred to nitrocellulose membrane, and probed with an antibody to $\mathrm{PTP} \mu$ (SK18). Fulllength $\mathrm{PTP} \mu$ is $\sim 200 \mathrm{kDa}$, and the proteolytically processed form of PTP $\mu$ migrates as two bands of $\sim 100$ and $110 \mathrm{kDa}$. Each immunoblot was stripped and reprobed with antibodies against vinculin to verify equal protein load per lane.

(Lemmon and McCloon, 1986). Thus, the NgCAM reaction product was weakest in peripheral retina, where RGC neurons are still differentiating at this age, and was much stronger near the central retina because of the greater number of axons growing toward the fissure in this region (Fig. 2A). No difference in $\mathrm{NgCAM}$ expression was observed between temporal or nasal retina. $\mathrm{PTP} \mu$ is expressed primarily by RGC axons in the OFL and cell bodies in the ganglion cell layer (Fig. 2B, arrowhead) (Burden-Gulley and Brady-Kalnay, 1999; Ledig et al., 1999b) but is also expressed in a region directly adjacent to the pigmented epithelium (Fig. 2B), which is the outer limit of the neural retina and is thought to be populated in part by mitotic neuroepithelial cells (Mey and Thanos, 1992). In serial sections of retina, РТР $\mu$ expression was weakest in the most peripheral and therefore least mature region of the retina (Fig. $2 B$ ) and was strongest in ventral-temporal retina near the optic nerve head (data not shown). Of interest, comparison of average pixel gray-level values in regions of nasal retina and temporal retina revealed that $\mathrm{PTP} \mu$ expression occurred as a step gradient (Fig. 2C), with a distinct transition at the optic fissure. Previously, РTP $\mu$ protein expression was examined in sections of chick retina from E6, E10, and E14 embryos (Ledig et al., 1999b). In that study, РТР $\mu$ was also detected in the OFL and ganglion cell layer, as well as in neuroepithelial cells adjacent to the pigmented epithelium. Yet no gradient of $\mathrm{PTP} \mu$ expression was observed in the OFL at the ages examined (Ledig et al., 1999b). This disparity in findings may be attributable to several reasons. First, in the present study, we examined $\mathrm{PTP} \mu$ expression at a different developmental age, E8. Second, we observed that the focal point of $\mathrm{PTP} \mu$ expression was in the ventral-temporal retina near the optic nerve head. РТP $\mu$ expression decreased from this ventral-temporal focal point to more peripheral retina. Therefore, if the study by Ledig (1999b) used sections from a different region of the retina, the gradient of $\operatorname{PTP} \mu$ would not have been apparent. Finally, the detection 


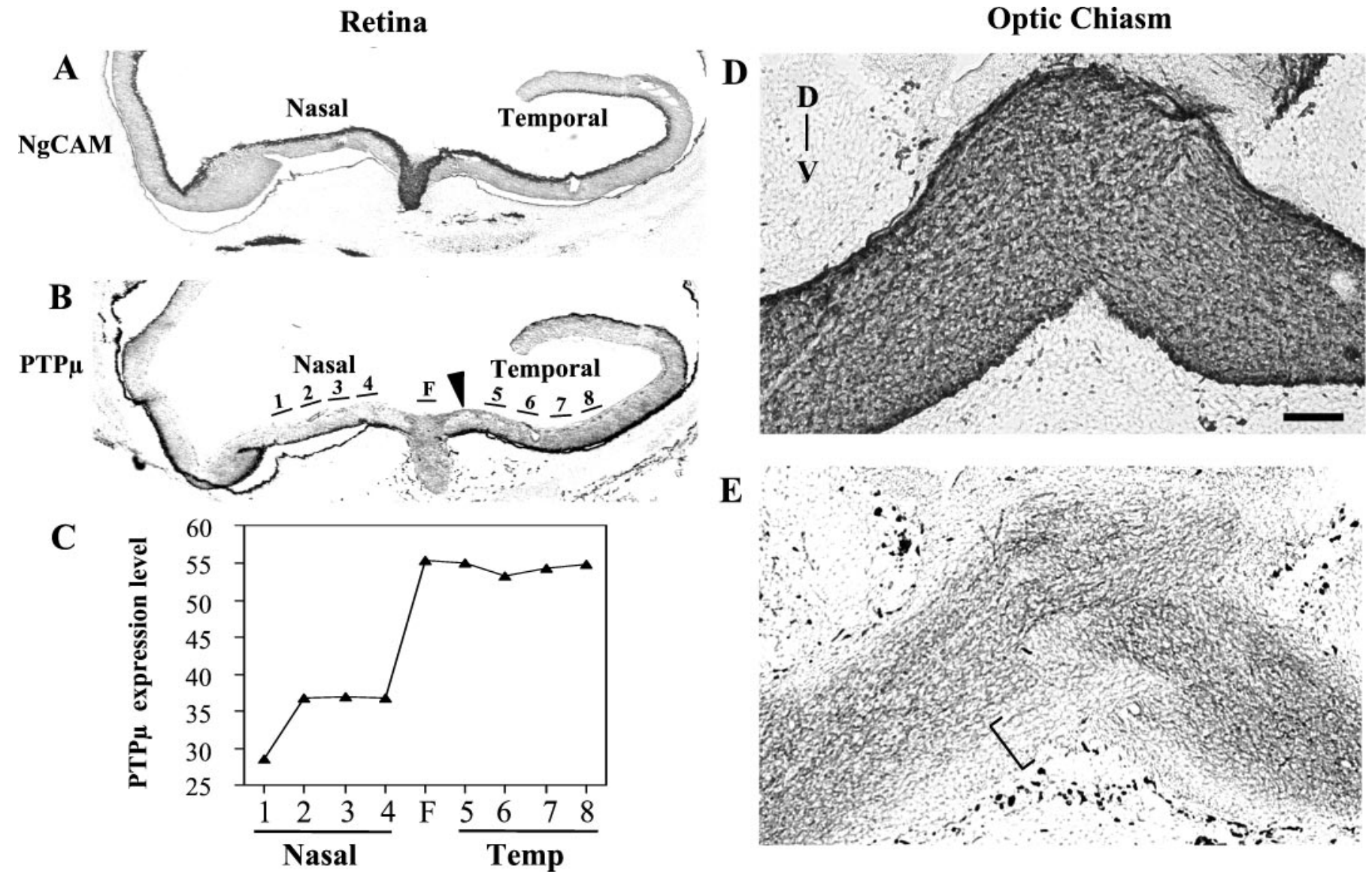

Figure 2. $\mathrm{PTP} \mu$ expression in the retina and optic chiasm at E8. E8 ventral retina (stage 32 ) was sectioned at $10 \mu \mathrm{m}$ intervals across the optic fissure and immunohistochemically labeled with antibodies against $\operatorname{NgCAM}(A)$ or $\operatorname{PTP} \mu(B)$. Nasal and temporal retina are present in each section and marked. The arrowhead in $B$ indicates the greater expression level of PTP $\mu$ in the OFL of the temporal retina. $C$, PTP $\mu$ expression level was determined by measuring the average pixel gray-level values throughout the width of the retina from the regions marked by the numbered lines in $B$. Coronal sections of an E8 chick head (stage 32.5) were immunohistochemically labeled with antibodies against NgCAM $(D)$ or PTP $\mu(E)$. Sections at the level of the optic chiasm are shown. The bracket in $E$ indicates the region of lower PTP $\mu$ expression in the ventral-medial chiasm, corresponding to axons from dorsal-nasal retina. The dorsal-to-ventral $(D-V)$ axis is indicated for $D$ and $E$. Scale bar, $175 \mu \mathrm{m}$. Temp, Temporal; $F$, fissure.

method we used for immunohistochemistry (Vectastain Elite $\mathrm{ABC}$ ) was more sensitive than standard immunofluorescence methods, because it included an amplification step through avidin-biotin complex formation. Because the RGC neurons are only one of several cell types that express $\mathrm{PTP} \mu$ in the retina, it is not surprising that the temporal gradient was not observed by immunoblot analysis of the entire retinal tissue (Fig. 1A). These results support the hypothesis that $\mathrm{PTP} \mu$ is differentially expressed in the developing retina.

$\mathrm{NgCAM}$ and PTP $\mu$ expression were also examined in sections of E8 chick head at the level of the optic nerve and optic chiasm (Fig. 2D,E). NgCAM was expressed by RGC axons throughout the optic nerve from the point at which the axons exited the retina and grew to the chiasm (Fig. 2D) and beyond to the tectum (Fig. $3 H$, arrowhead). In cross sections of the optic nerve and chiasm, the $\mathrm{NgCAM}$ expression was continuous, with no change in intensity (Fig. 2D). When PTP $\mu$ expression was examined in adjacent sections, the RGC axons were divided into two groups, with the axons expressing the highest levels of $\mathrm{PTP} \mu$ remaining as a separate group from those expressing lower levels of $\mathrm{PTP} \mu$ (indicated by a bracket in Fig. $2 E$ ). The axons with the highest level of $\mathrm{PTP} \mu$ expression were localized to a dorsal and lateral region at the anterior optic chiasm, suggesting that they originated from ventral-temporal retina (Thanos and Bonhoeffer, 1983). Because neighboring RGC axons of the retina maintain their spatial relationships as they grow through the optic nerve (Thanos and Bonhoeffer, 1983), it is intriguing to speculate that $\mathrm{PTP} \mu$ may be involved in the axon-axon adhesion and communication that regulates this process.

\section{Expression of PTP $\mu$ in the optic tectum}

We also examined whether $\mathrm{PTP} \mu$ was expressed in a gradient in the developing tectum. Lysates were made from anterior or posterior tectum at different developmental ages, separated by SDSPAGE, and immunoblotted for $\mathrm{PTP} \mu$ (Fig. 1B). РТР $\mu$ was expressed at higher levels in anterior tectum than posterior tectum from E6 to E12 embryos. During development, the first RGC axons reach the anterior pole of the tectum in a ventral-lateral position by E6 (Thanos and Bonhoeffer, 1983) and then grow progressively across the surface of the tectum in a dorsal-posterior direction, forming the SO layer. Interestingly, the anterior gradient of PTP $\mu$ becomes more apparent by E8 (Fig. $1 B$ ), just before the point at which the first RGC axons are known to invade the tectum to form synapses in the SGFS layer (LaVail and Cowan, 1971; Mey and Thanos, 1992). Axon invasion and synapse formation in the tectum continue beyond E12, with axons 

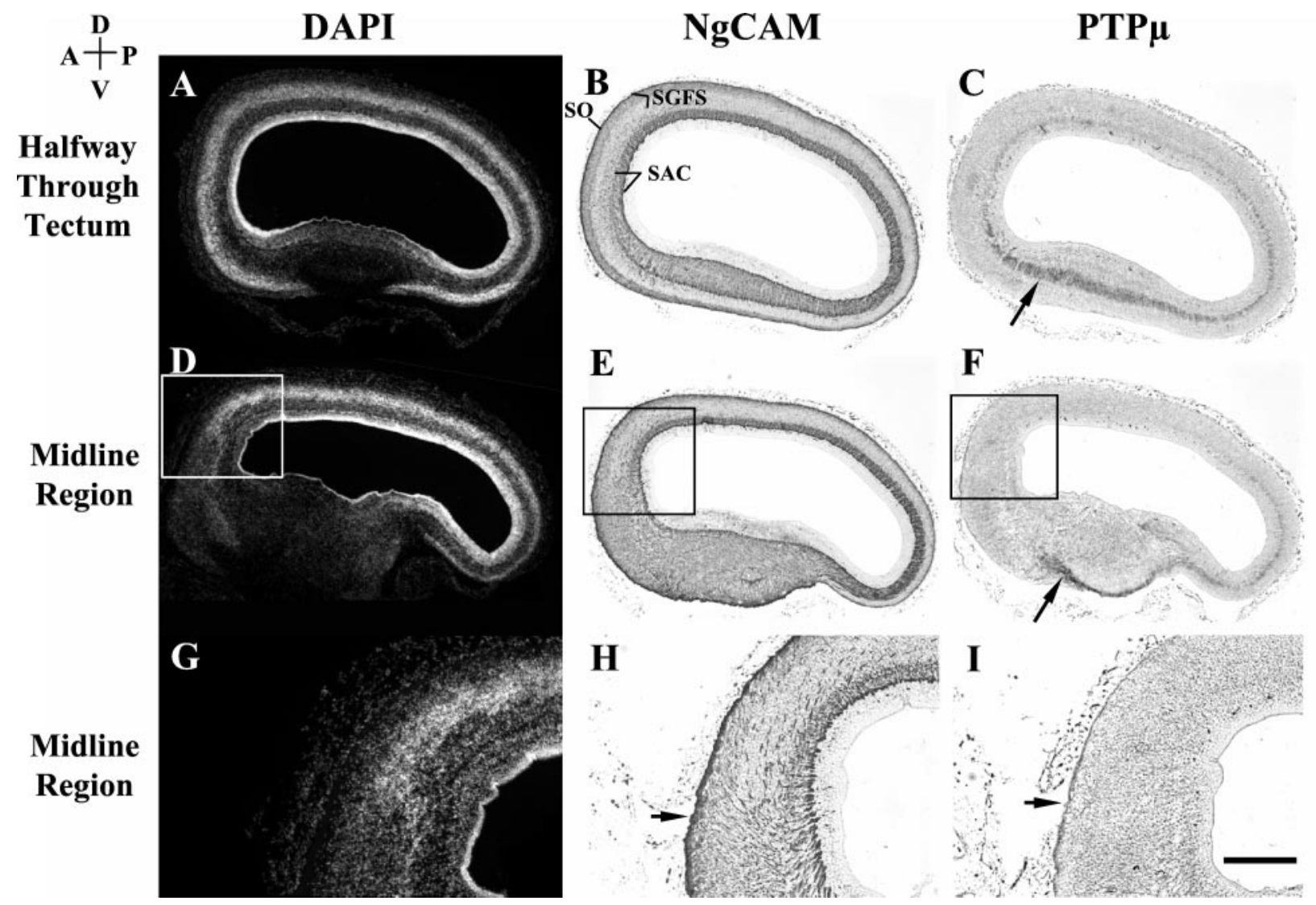

Figure 3. РТP $\mu$ expression in sagittal sections of the optic tectum at E8. E8 (stage 34) optic tectum was sectioned in a sagittal orientation at $10 \mu \mathrm{m}$ intervals. Sections were immunohistochemically labeled with DAPI to show cell nuclei $(A, D, G)$ or with antibodies against $\operatorname{NgCAM}(B, E, H)$ or PTP $\mu$ $(C, F, I)$. PTP $\mu$ expression occurs in the SO layer (arrowhead in $I$ ), the SGFS layer, and a subset of fibers in the SAC layer (arrow in $C$ and $F$ ). NgCAM is expressed in the SO layer (arrowhead in $H$ ). Insets in $D-F$ indicate the high-magnification images shown in $G-I$, respectively. The dorsal $(D)$-to-ventral $(V)$ and anterior $(A)$-to-posterior $(P)$ axes are indicated. Scale bar, $250 \mu \mathrm{m}$.

from temporal retina forming synapses in the more anterior regions of the tectum, whereas axons from nasal retina form synapses in posterior tectal regions (Mey and Thanos, 1992). The anterior gradient of $\mathrm{PTP} \mu$ was maintained at E12 (Fig. 1B), suggesting that $\mathrm{PTP} \mu$ may have a sustained function in RGC axon targeting and innervation of the tectum.

To gain a better understanding of the role of $\operatorname{PTP} \mu$ in the developing tectum, we examined $\mathrm{PTP} \mu$ expression in sagittal sections of E8 optic tectum. At late E8-E9, the first RGC axons invade the SGFS layer of the tectum, beginning with a site in the anterior tectum that is ventral-lateral in location (Rager, 1980). At $\mathrm{E} 8, \mathrm{NgCAM}$ was observed in three distinct fiber layers (Fig. $3 B, E, H)$. The outermost layer of expression was the SO layer, composed of RGC axons. Within the SO layer, $\mathrm{NgCAM}$ was expressed at the anterior edge and a portion of the dorsal tectum (Fig. 3H, arrowhead). The next region of NgCAM labeling was just below the SO and consisted of axons in the SGFS layer (Fig. $3 B$ ). The central-most region of $\mathrm{NgCAM}$ labeling was the axons of the stratum album centrale (SAC) layer (Fig. $3 B$ ) that originate from multipolar neurons of the stratum griseum centrale, which form the main tectal output to higher brain centers (Deng and Rogers, 1998; Wu et al., 2000). DAPI labeling of nuclei in adjacent sections (Fig. $3 A, D, G$ ) was the reciprocal of the NgCAM labeling pattern, suggesting that the cellular (DAPI) and plexiform (NgCAM) layers were distinct.

PTP $\mu$ labeling in E8 tectum was observed primarily in two layers (Fig. 3C,F,I). A weak reaction product was detected in the SO layer at the anterior-most pole (Fig. 3I, arrowhead). Therefore, the RGC axons maintain $\mathrm{PTP} \mu$ expression throughout growth to and association with the optic tectum. The majority of labeling occurred in the SAC axons (Fig. 3C) but appeared to be only a subset of those expressing NgCAM. SAC axons of the ventral-anterior tectum expressed higher levels of $\mathrm{PTP} \mu$ than those of dorsal-posterior regions (Fig. 3C, arrow), corresponding to Western blot analysis of tectum at E8. In the midline region, РТР $\mu$ expression was confined to the ventral-most portion of the tectum (Fig. $3 F$, arrow), which most likely corresponds to a subset of SAC axons that coalesce to form the main tectal output to the nucleus rotundus of the diencephalon (for review, see Rager, 1980). Of interest, recent studies have shown that axons of the SAC are ordered topographically and project in an organized manner to higher brain centers (Deng and Rogers, 1998; Wu et al., 2000). $\mathrm{PTP} \mu$ expression in a subset of the SAC axons is suggestive of a role in maintaining topographic order en route to higher brain centers. A third region of weak PTP $\mu$ expression was observed in the SGFS layer (Fig. $3 C$ ). $\mathrm{PTP} \mu$ expression in the SGFS was previously described to occur in a radial manner at E6, suggesting expression by migrating neurons or radial glia (Ledig et al., 1999b). In that study, horizontal sections of the tectum were analyzed. When we examined $\mathrm{PTP} \mu$ expression in horizontal sections of E8 tectum, a similar radial expression pattern was observed in the SGFS (Fig. $4 B-D$ ). Of interest, PTP $\mu$ expression 

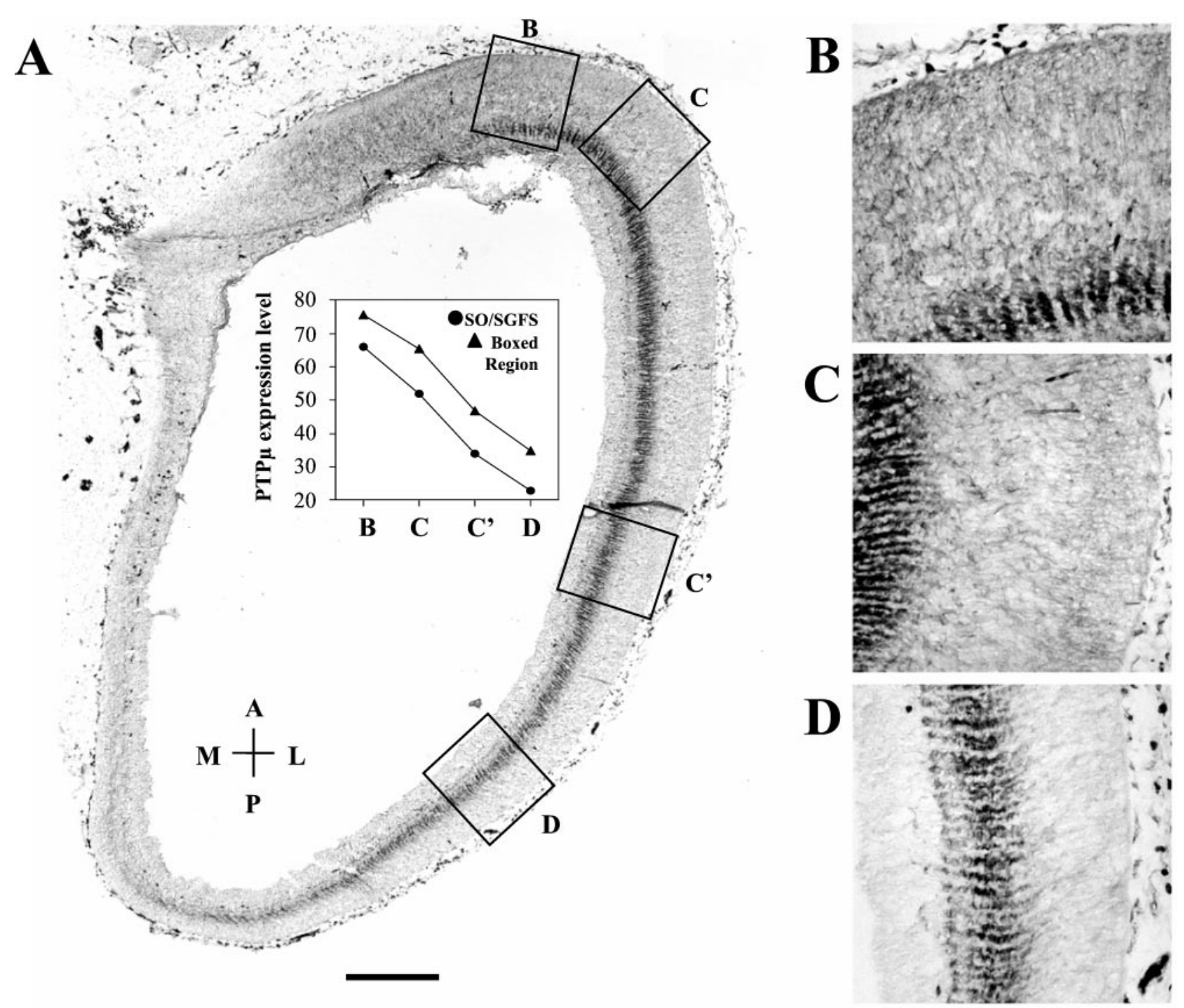

Figure 4. $\mathrm{PTP} \mu$ is expressed in a smooth anterior-to-posterior gradient in the E8 optic tectum. E8 (stage 34) optic tectum was sectioned in a horizontal plane at $10 \mu \mathrm{m}$ intervals. Sections were immunohistochemically labeled with antibodies against PTP $\mu$. $A$, PTP $\mu$ was expressed in a descending anterior-to-posterior gradient. The section shown was taken at a level $\sim 700 \mu \mathrm{m}$ below the dorsal surface of the tectum. The graph inset in $A$ indicates the $\mathrm{PTP} \mu$ expression level as determined from the average gray-level values of the pixels within the boxed regions in $A$. Measurements were made from each boxed region throughout the width of the tectum (filled triangles) and also from a smaller portion of each boxed region that included only the SO and SGFS layers (filled circles). B, High-magnification image of anterior tectum showing radial expression of PTP $\mu$ in outer tectal layers. $C$, High-magnification image of anterior-lateral tectum showing radial expression of PTP $\mu$ in the SGFS layer primarily. $D$, High-magnification image of posterior-lateral tectum showing lower-level expression of PTP $\mu$ in outer tectal layers. The anterior- $(A)$ to-posterior $(P)$ and medial $(M)$-to-lateral $(L)$ axes are indicated. Scale bar, $325 \mu \mathrm{m}$.

in the SGFS occurred in a smooth descending gradient from anterior to posterior tectum, as determined by measurement of pixel gray-level values in the regions defined by the boxes in Figure $4 A$ (see graph inset). The region of the SGFS that expressed the greatest level of $\mathrm{PTP} \mu$ was approximately the site at which the first RGC axons invade the deeper tectal layers to form synapses (Rager, 1980). Therefore, $\mathrm{PTP} \mu$ is upregulated in the optic tectum just before the point at which the first RGC axons reach their tectal target and may be involved in regulating the migration to and innervation of the SGFS layer.

\section{PTP $\mu$ promotes neurite outgrowth from the ventral nasal retina}

The distinct pattern of $\mathrm{PTP} \mu$ expression in the developing retina and tectum is suggestive of a role in axon guidance. $\mathrm{PTP} \mu$ promotes neurite outgrowth from retinal explants when used as a substrate in culture, although the outgrowth is not as robust as that promoted by other CAMs such as N-cadherin or L1 (BurdenGulley and Brady-Kalnay, 1999) and therefore may occur from only a subset of RGCs. Comparison of neurite outgrowth on $\operatorname{PTP} \mu, \mathrm{N}$-cadherin, or laminin substrates from distinct retinal regions revealed that the spatial location of the RGC cell body determined its response to the substrate. When retinal explants are cultured in vitro, axons from RGC neurons extend from the side of the explant that was formerly closest to the optic fissure (Halfter et al., 1983); therefore, outgrowth from this region of each explant was examined for the following analyses. On a laminin substrate, robust neurite outgrowth occurred from all regions of the retina (Figs. $5 A, 6 A$ ), with the longest neurites 

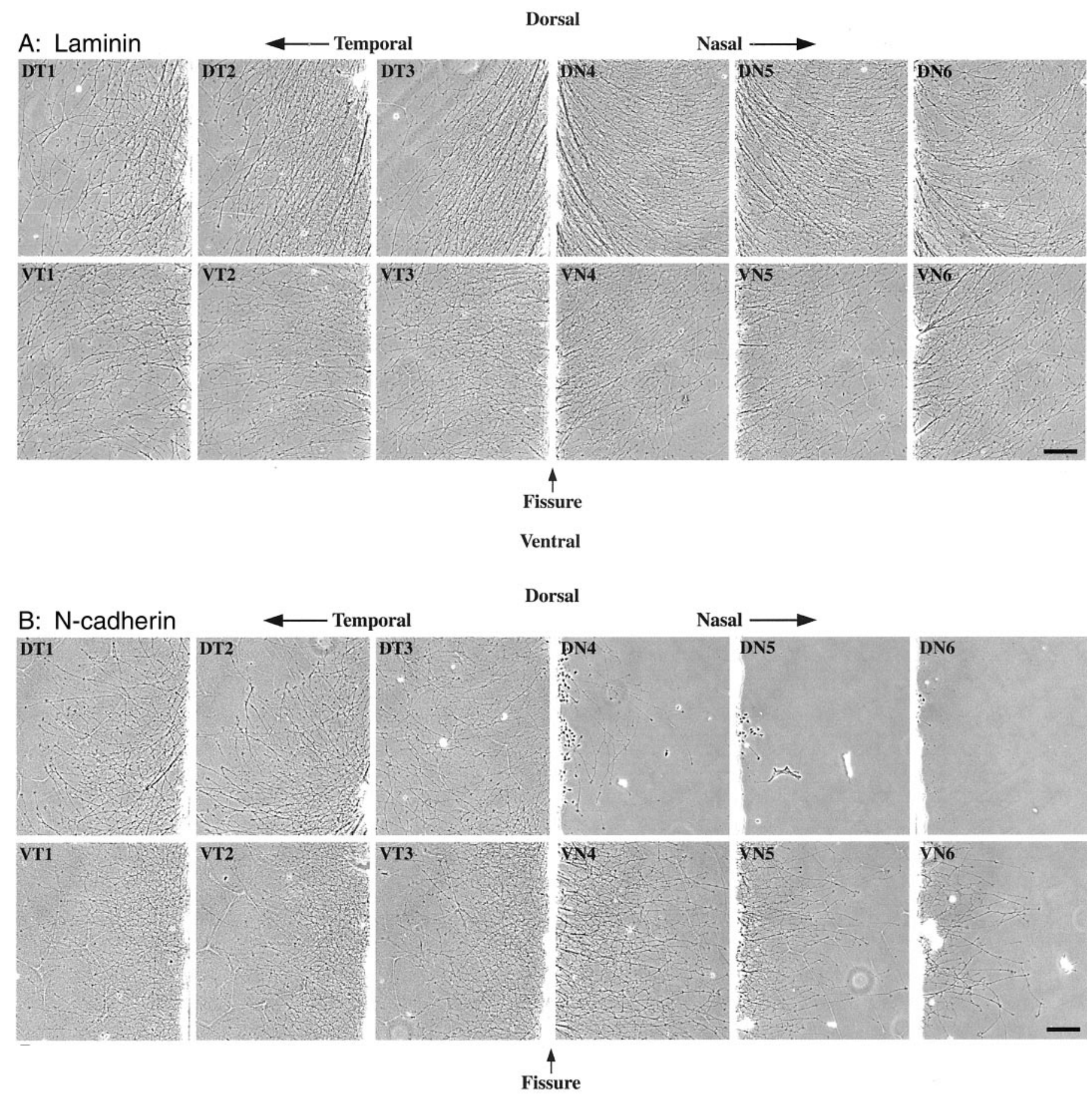

Ventral

Figure 5. Neurite outgrowth on laminin, N-cadherin, or PTP $\mu$ is dependent on the site of origin of the RGC cell body. Explants from E8 (stage 32) retina were cut parallel to the optic fissure, and explants from both nasal and temporal retina were cultured on laminin $(A)$, N-cadherin $(B)$, or PTP $\mu$ $(C)$ substrates. Images were acquired after $24(A, B)$ or $72(C) \mathrm{hr}$ in culture. Note that the images shown were acquired at a location corresponding to the outer third of each explant so that clear nasal $(N)$ /temporal $(T)$ and dorsal $(D)$ /ventral $(V)$ differences could be observed. The letters shown in each panel correspond to the position within the retina (e.g., $D T=$ dorsal temporal retina). The numbers in each panel indicate the explant number, with explants 1 and 6 being taken from the most peripheral regions of the retina. Scale bar, $150 \mu \mathrm{m}$. (Figure 5 continues.)

growing out from the dorsal-nasal retina $(n=3$ separate experiments). On both $\mathrm{N}$-cadherin and $\mathrm{PTP} \mu$, the majority of neurite outgrowth occurred from RGCs of ventral retina (Fig. 5B,C). On N-cadherin, robust neurite outgrowth occurred from both ventral-nasal retina and ventral-temporal retina (Figs. 5B, 6B), although neurites of ventral-temporal retina tended to be more fasciculated ( $n=3$ separate experiments). In addition, neurite outgrowth was robust from dorsal-temporal retina, although almost no neurite outgrowth occurred from dorsal-nasal retina on $\mathrm{N}$-cadherin (Figs. $5 B, 6 B$ ). 

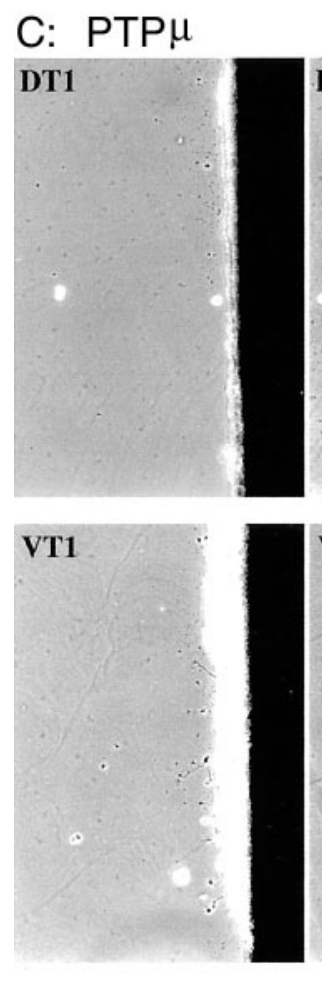

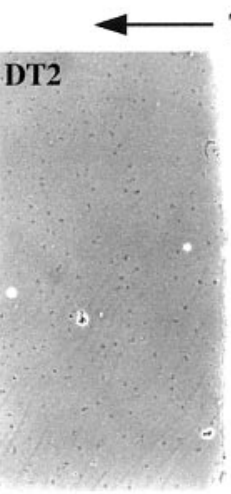

Tempora

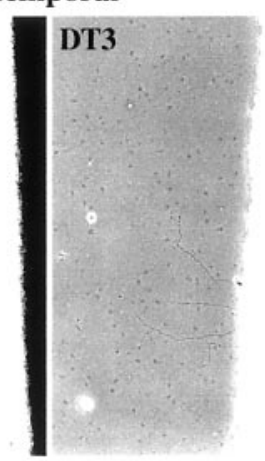

VT2

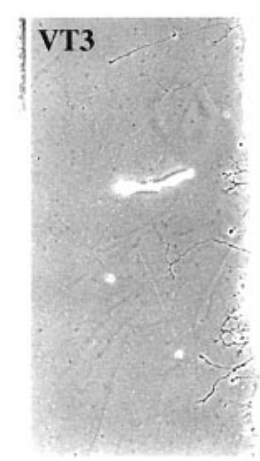

Dorsal
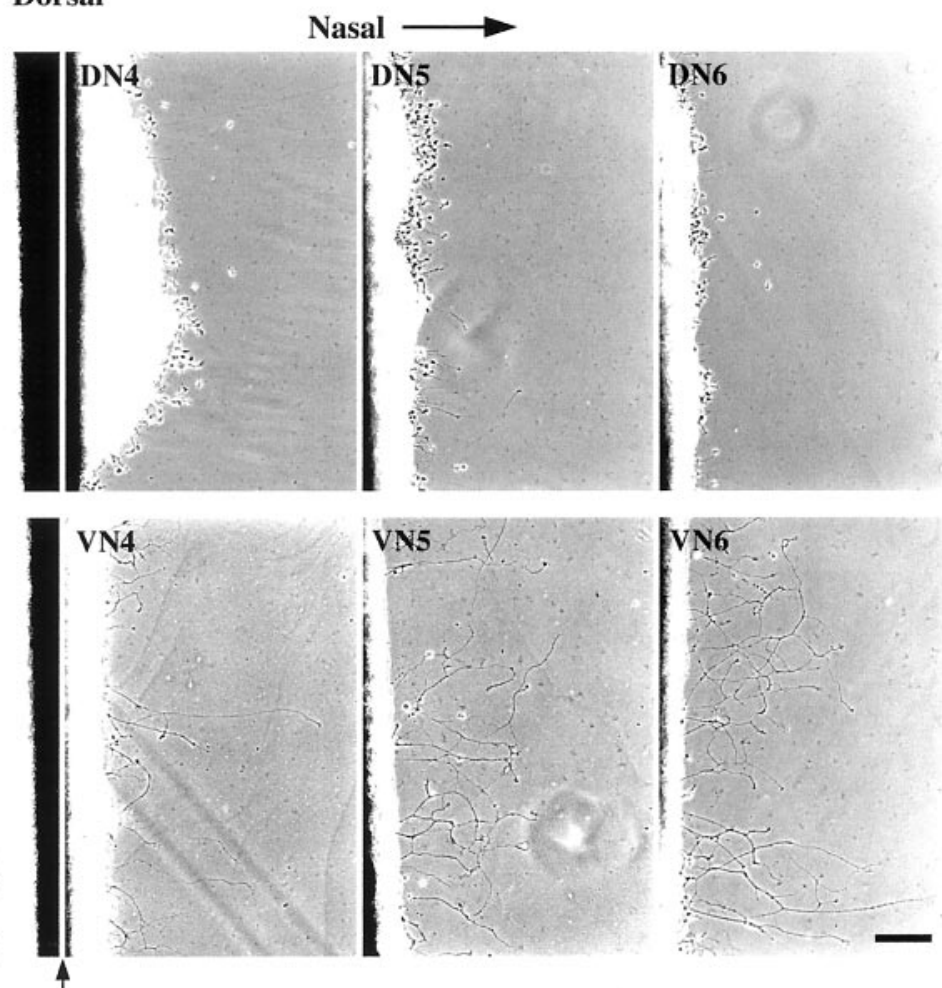

Fissure

\section{Ventral}

Figure 5 continued.

The response of RGC neurites to a PTP $\mu$ substrate (Figs. $5 C$, $6 C$ ) was distinctly different from that observed on laminin or $\mathrm{N}$-cadherin. The greatest number of neurites extended from RGCs of ventral-nasal retina. Neurites from ventral-temporal retina tended to be shorter, much fewer in number, and in some cases completely absent ( $n=4$ separate experiments). For the neurite outgrowth assay, the surface of the culture dish was coated with a high concentration of $\mathrm{PTP} \mu$ protein. Therefore, a high level of $\mathrm{PTP} \mu$ is permissive for outgrowth from neurites expressing lower levels of $\mathrm{PTP} \mu$ (nasal) but somewhat inhibitory for neurites expressing higher levels of $\mathrm{PTP} \mu$ (temporal). A large number of migratory cells originated from dorsal-nasal retina (Fig. 5C), which is a less mature region of the retina at E8 (Halfter et al., 1985), suggesting that $\mathrm{PTP} \mu$ may play a role in cell migration during retinal development. These migratory cells were shown previously to be composed of RGC neurons and bipolar neurons (Burden-Gulley and Brady-Kalnay, 1999). These data demonstrate that the response of an RGC to a PTP $\mu$ substrate is dependent on the spatial location of its cell body in the retina.

\section{PTP $\mu$ inhibits outgrowth of neurites from temporal retina}

The differential outgrowth of RGC neurites on a $\mathrm{PTP} \mu$ substrate (Figs. 5C, 6C) suggested that $\mathrm{PTP} \mu$ may influence the guidance of specific populations of RGC axons. To examine this issue, retinal explants from E8 retina were cultured on alternating lanes of $\mathrm{PTP} \mu, \mathrm{N}$-cadherin, and laminin substrates using the method of Bonhoeffer (Vielmetter et al., 1990). For these experiments, the explants were cut across the optic fissure such that both nasal and temporal retina regions were present in the same explant. The explants were selected from ventral retina because the peak of
РТР $\mu$ expression was observed in ventral retina (Fig. 2). Analysis of neurite outgrowth at $48 \mathrm{hr}$ after culture revealed striking differences in the responses of nasal versus temporal axons to the $\mathrm{PTP} \mu$ substrate (Fig. $7 A, B$ ). RGC neurites from the nasal retina (Fig. 7A) were observed to initiate growth on $\mathrm{PTP} \mu$ and frequently crossed onto $\mathrm{PTP} \mu$ from the adjacent N-cadherin lanes. Some of these neurites remained on the $\mathrm{PTP} \mu$ substrate, whereas others crossed back to N-cadherin. In contrast, when given a choice between two growth substrates, neurites from the temporal retina grew exclusively on the $\mathrm{N}$-cadherin substrate, with no initiation of growth or crossover onto the $\mathrm{PTP} \mu$ substrate lanes (Fig. $7 B$ ). Growth cones of temporal neurites were observed to grow right up to the border between $\mathrm{N}$-cadherin and $\mathrm{PTP} \mu$ and stall, but were never observed to cross over. Several growth cones were collapsed in appearance, suggesting that $\mathrm{PTP} \mu$ may be inhibitory to temporal neurite growth. Similar results were observed when outgrowth was examined on alternating lanes of РТР $\mu$ and laminin (data not shown). In contrast, both nasal and temporal neurites crossed freely when cultured on alternating lanes of $\mathrm{N}$-cadherin and laminin (Fig. 7C,D) (Lemmon et al., 1992). Therefore, temporal neurites exhibited a preference for outgrowth on $\mathrm{N}$-cadherin or laminin over PTP $\mu$.

To examine whether $\mathrm{PTP} \mu$ had an inhibitory effect that was specific to temporal neurites, we performed a growth cone collapse assay (Stepanek et al., 2001). In this assay, purified PTP $\mu$ or $\mathrm{N}$-cadherin was applied to cultures of retinal neurites for $10 \mathrm{~min}$, and then the cultures were fixed and growth cones from nasal and temporal retina were analyzed for collapse. Application of $\mathrm{N}$-cadherin resulted in a low level of growth cone collapse that was equivalent in nasal and temporal retina and was similar to the 

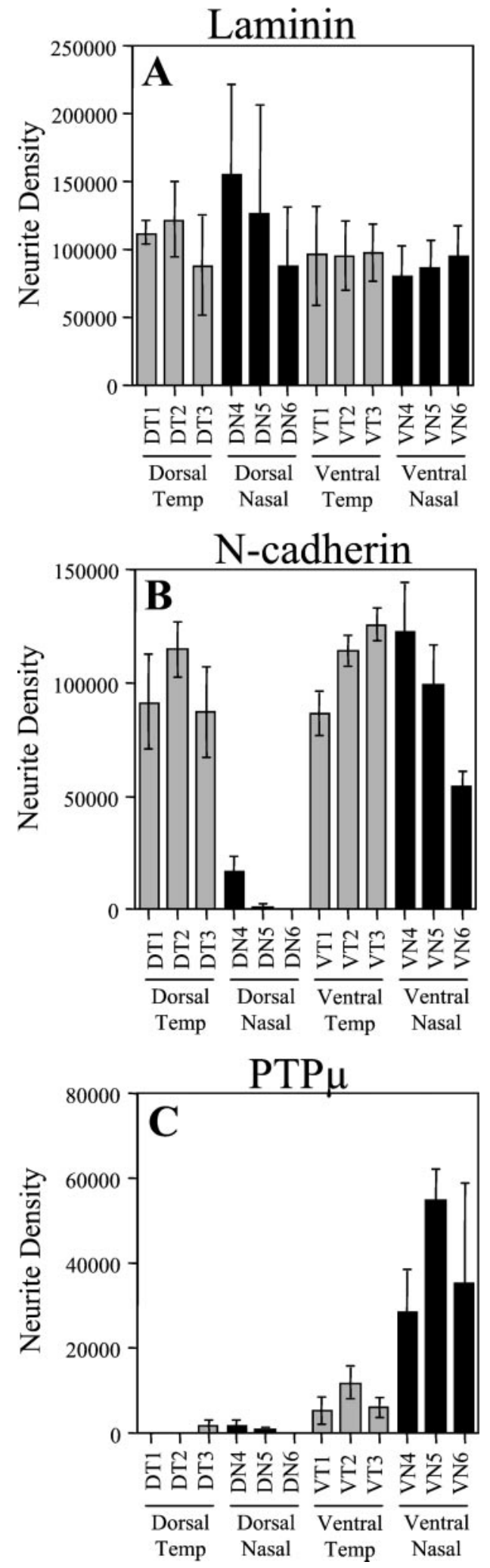

Figure 6. Quantification of neurite outgrowth on laminin, N-cadherin, and $\mathrm{PTP} \mu$. E8 (stage 32) retina explants were cultured on laminin $(A)$ $(n=3)$, N-cadherin $(B)(n=3)$, or PTP $\mu(C)(n=4)$ for $24(A, B)$ or $72(C) \mathrm{hr}$. Neurite density was measured from each retina region, and the data from outgrowth on a single substrate were combined and plotted as shown (mean $\pm \mathrm{SEM}$ ). The letters $D, \mathrm{~V}, N$, and $T$ indicate dorsal, ventral, nasal, and temporal, respectively. Temp, Temporal. effect of control RPMI medium application $(n=3$ separate experiments each) (Fig. 8B). In contrast, application of PTP $\mu$ resulted in a significant increase in collapse $(p<0.0001)$ that was specific to temporal growth cones (Fig. $8 B$ ) but had no effect on nasal growth cones ( $n=5$ separate experiments). Similar results were observed after a 20 min application of $\mathrm{PTP} \mu$ (data not shown). An example of a collapsed growth cone after PTP $\mu$ application is shown in Figure $8 A$. These results confirm the phenotype observed using the lane assay and indicate a specific growth-inhibitory effect of $\mathrm{PTP} \mu$ on RGCs of temporal origin. Together, these results suggest that $\mathrm{PTP} \mu$ may play an active role in the guidance of RGC axons during growth to and innervation of the optic tectum.

\section{DISCUSSION}

РТР $\mu$ is a homophilic adhesion molecule that is capable of transducing signals in response to adhesion via changes in tyrosine phosphorylation. We have shown previously that $\mathrm{PTP} \mu$ promotes neurite outgrowth from retinal explants when used as a substrate in vitro (Burden-Gulley and Brady-Kalnay, 1999). Here, we demonstrate that $\mathrm{PTP} \mu$-mediated neurite outgrowth is dependent on the spatial location of the RGC cell body: RGC neurons of ventral-nasal retina exhibited the most robust neurite outgrowth on $\mathrm{PTP} \mu$, whereas RGC neurons of ventral-temporal retina grew poorly on $\mathrm{PTP} \mu$. Examination of $\mathrm{PTP} \mu$ expression in an E8 retina revealed a step gradient with higher PTP $\mu$ expression in ventral-temporal than in ventral-nasal retina. A similar gradient was detected in the optic nerve and chiasm, suggesting that $\mathrm{PTP} \mu$ may be involved in maintaining the relationships between neighboring RGC axons during growth to the tectum. Expression of РТP $\mu$ in the developing optic tectum occurred in a smooth descending anterior-to-posterior gradient, with radial expression in the SGFS layer of anterior tectum. Finally, differential neurite responses occurred from retinal explants cultured on alternating lanes of PTP $\mu$ with N-cadherin or laminin. Neurites of nasal origin grew readily on $\mathrm{PTP} \mu$, whereas neurites from temporal retina actively avoided $\mathrm{PTP} \mu$ lanes. In accordance with these findings, the application of $\mathrm{PTP} \mu$ to retinal neurites resulted in the specific collapse of growth cones from temporal retina. Together, these results indicate that $\mathrm{PTP} \mu$ signaling actively influences RGC neurite outgrowth and that $\mathrm{PTP} \mu$ may play an important role during the formation of retinal projections to the tectum.

РТР $\mu$ may have several distinct roles during development of the chick visual system. One of the earliest roles may be in lamination of the retina. In support of this idea, РTP $\mu$ expression in the retina was high in the cells adjacent to the pigmented epithelium at the outer limits of the retina. These cells are a mixed population of premitotic and postmitotic cells that differentiate and migrate to their final site in the retina (Prada et al., 1991). А РТР $\mu$ substrate promotes cell migration from less mature regions of retina in culture, suggesting that $\mathrm{PTP} \mu$ may play a role in the cell migration that occurs during formation of distinct retinal layers.

Once the RGC neurons migrate to the inner retina, they extend axons toward the optic fissure, and the axons coalesce to form the optic nerve. In the E8 retina, $\mathrm{PTP} \mu$ expression in the OFL occurs coincidently with RGC axon outgrowth. PTP $\mu$ expression is elevated in a subset of RGC cell bodies throughout the E8 retina, with the majority of these cell bodies found in temporal retina. The axons of temporal RGC neurons also express higher levels of $\mathrm{PTP} \mu$ than RGC axons of nasal retina. As the axons grow 

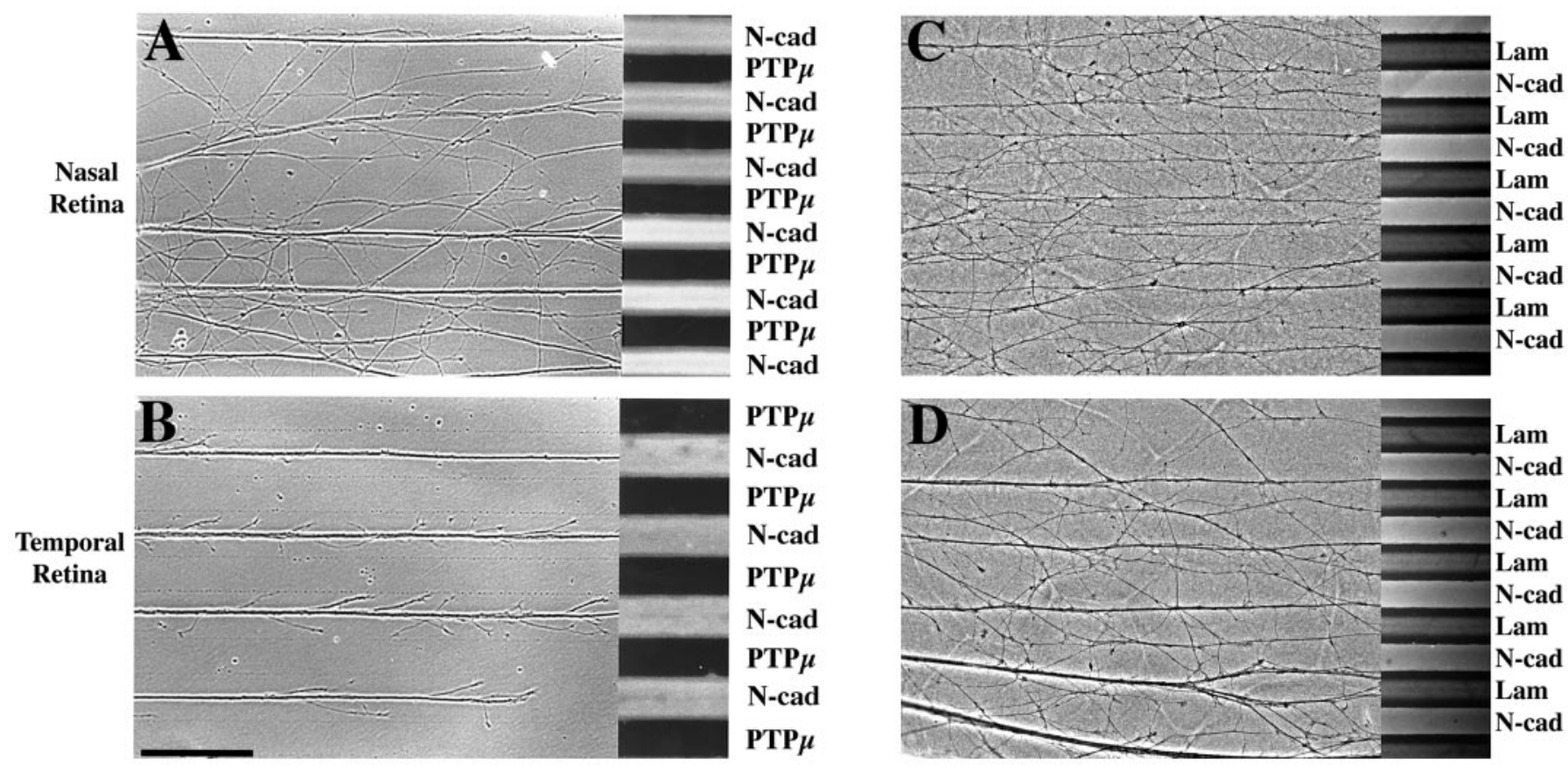

Figure 7. Neurite outgrowth on alternating lanes of $\mathrm{PTP} \mu, \mathrm{N}$-cadherin $(N$-cad), and laminin (Lam). E8 (stage 32.5) retina explants were cultured for $48 \mathrm{hr}$ on alternating lanes of $\mathrm{PTP} \mu$ and $\mathrm{N}$-cadherin $(A, B)$ or N-cadherin and laminin $(C, D)$. $A$, Neurites from nasal retina grew well on $\mathrm{N}$-cadherin and РТP $\mu$, whereas neurites from temporal retina $(B)$ actively avoided PTP $\mu$ lanes to grow exclusively on N-cadherin. Neurites of nasal $(C)$ and temporal $(D)$ retina crossed freely between alternating lanes of N-cadherin and laminin. Scale bar, $150 \mu \mathrm{m}$.

through the optic nerve en route to the tectum, they roughly maintain neighboring relationships (Rager, 1980). This was reflected by $\mathrm{PTP} \mu$ expression in the chiasm region, in which the ventral-temporal axons expressing higher levels of $\mathrm{PTP} \mu$ were segregated from dorsal-nasal axons. This differential expression pattern may be one means by which the RGC axons communicate with one another to maintain their neighboring relationships during growth through the optic nerve.

The level of PTP $\mu$ expression in RGC axons of the developing retina is lower than that of other CAMs, such as $\mathrm{N}$-cadherin and $\mathrm{NgCAM}$, suggesting that the main role of $\mathrm{PTP} \mu$ may be in signaling in response to cell-cell adhesion. Multiple CAMs and extracellular matrix molecules act in concert to promote growth of RGC axons through the optic nerve (for review, see Mey and Thanos, 1992; Thanos and Mey, 2001). Neurite outgrowth on $\mathrm{PTP} \mu$ is not as robust as growth on other CAM substrates (Burden-Gulley and Brady-Kalnay, 1999). One explanation for this result is that a $\mathrm{PTP} \mu$ adhesion-mediated signal may stimulate neurite outgrowth from only a subset of RGCs. The differential neurite outgrowth observed on a $\mathrm{PTP} \mu$ substrate suggests that PTP $\mu$ is permissive for neurite outgrowth from RGC axons expressing low levels of $\mathrm{PTP} \mu$ (nasal retina) but is clearly less permissive for RGC axons expressing higher levels of $\operatorname{PTP} \mu$ (temporal retina). This inverse relationship suggests that once a threshold level of $\mathrm{PTP} \mu$ expression in the cells is reached, the role of $\mathrm{PTP} \mu$ may switch from being a permissive protein to being an instructive and probably growth-inhibitory protein.

The PTP $\mu$-mediated collapse of temporal growth cones lends additional support to the idea that $\mathrm{PTP} \mu$ specifically regulates the growth of a subpopulation of RGCs. The collapse response occurred within 10 min of $\mathrm{PTP} \mu$ application, which is in the time frame of a signaling response. Thus, the stimulation of cells with PTP $\mu$ is likely to mimic PTP $\mu$-mediated adhesion and signaling.
It is feasible that the PTP $\mu$-mediated collapse signal could occur in vivo, because it was observed in the presence of a strong growth-promoting molecule (laminin) in vitro.

It has been shown previously that the first RGC axons reach the anterior edge of the tectum by E6 but wait until early E9 before invading the SGFS layer to form synapses (Rager, 1980). Therefore, it is conceivable that after reaching the anterior tectum, where $\mathrm{PTP} \mu$ levels are high, temporal RGC axons cease their forward growth because of a PTP $\mu$ adhesion-mediated signal. A stall in forward growth would allow growth cones of temporal axons to explore the local environment to locate appropriate innervation sites. In contrast, nasal RGC axons are capable of continued growth to posterior tectal regions, because $\mathrm{PTP} \mu$ is permissive for nasal axon growth.

In a previous study in vitro, RGC growth cones were observed to stall, and in some cases collapse, in response to contacting borders between permissive growth substrates such as laminin, N-cadherin, and L1 (Burden-Gulley et al., 1995). Growth cone contact with these substrates resulted in cytoskeletal restructuring (Burden-Gulley and Lemmon, 1996) and a dramatic morphology change (Burden-Gulley et al., 1995), which was probably a response to CAM-mediated signaling. $\mathrm{PTP} \mu$ is thought to signal in response to adhesion. Of interest, $\mathrm{PTP} \mu$-mediated signaling has been shown previously to be cell-density dependent: $\mathrm{PTP} \mu$ dependent adhesion at cell contact sites induces association with an intracellular scaffolding protein, receptor for activated $\mathrm{C}$ kinase (RACK-1), that is a downstream mediator of a PTP $\mu$ signal (Rosdahl et al., 2002; Mourton et al., 2001). The higher concentration of $\mathrm{PTP} \mu$ on temporal axons may allow them to respond to a $\mathrm{PTP} \mu$ signal after reaching the $\mathrm{PTP} \mu$-rich anterior tectum. Perhaps temporal neurons express intracellular proteins that are distinct from nasal neurons and thus allow for a differential response to a $\mathrm{PTP} \mu$ signal. Once the RGC axons delve into the 

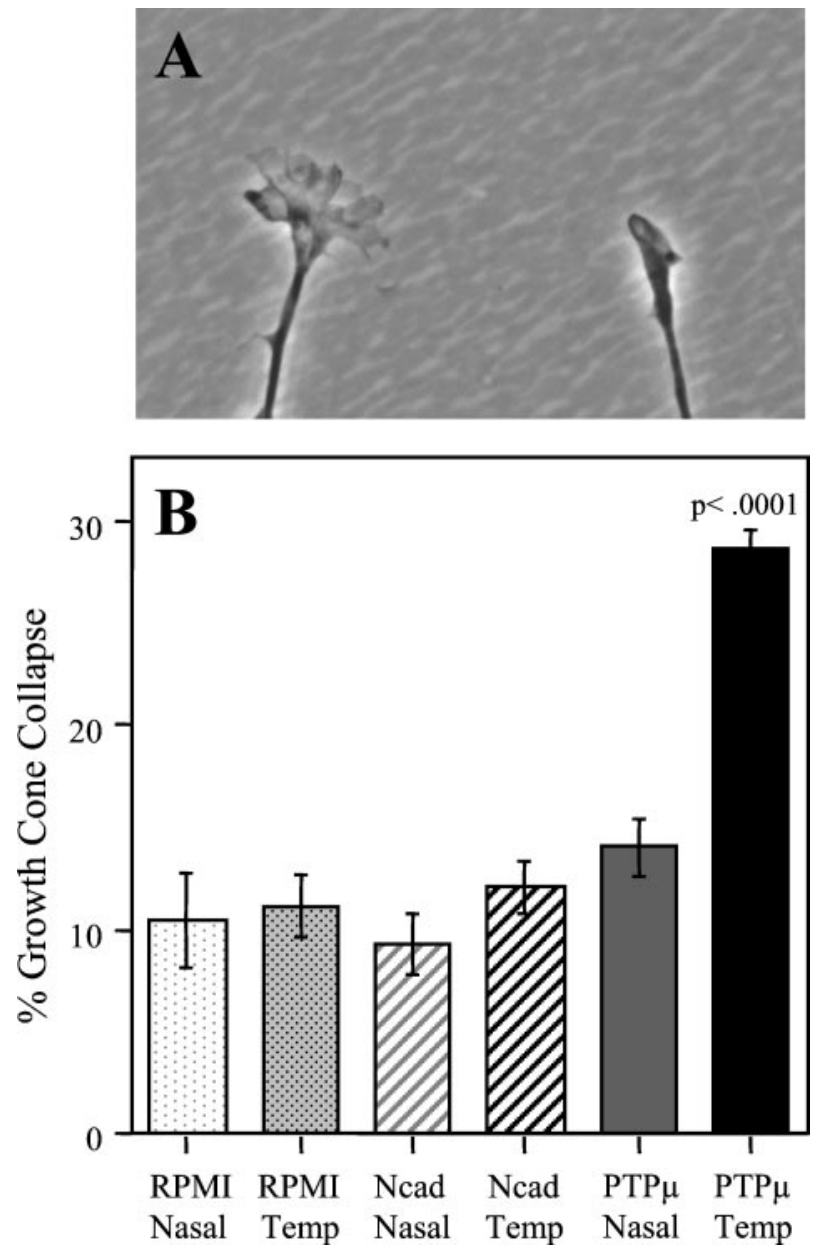

Figure 8. $\mathrm{PTP} \mu$ stimulates the collapse of growth cones from temporal (Temp) retina. E8 (stage 32) retina explants were cultured on laminin for $22 \mathrm{hr}$ and then treated with RPMI-1640 medium ( $n=3$ experiments), $\mathrm{N}$-cadherin ( $\mathrm{Ncad})(n=3$ experiments), or PTP $\mu$ ( $n=5$ experiments) for $10 \mathrm{~min}$. The cells were fixed, and growth cones from nasal and temporal regions of each explant were scored for collapse. An example of a collapsed growth cone after stimulation with $\mathrm{PTP} \mu$ is shown in $A$. Note the complete loss of lamellipodial veils in the collapsed growth cone on the right compared with the growth cone on the left. B, Quantification of the growth cone collapsing effect. The percentage of collapsed growth cones (mean $\pm \mathrm{SEM}$ ) is shown for treatment with the control RPMI medium, N-cadherin, or PTP $\mu$ proteins. Stimulation with $\mathrm{PTP} \mu$ resulted in a significant increase in growth cone collapse that was exclusive to growth cones from temporal retina.

tectum, $\mathrm{PTP} \mu$ most likely works in concert with other guidance molecules to fine-tune the innervation pattern within the deeper tectal layers (Inoue and Sanes, 1997; Miskevich et al., 1998).

РТP $\mu$ is expressed at high levels in the SAC layer within the tectum, with a ventral-anterior (high) to dorsal-posterior (low) gradient. The SAC layer is composed of axons from cells of the stratum griseum centrale layer, which form the main tectal output to higher brain centers. Recent studies have shown that the SAC axons are ordered topographically and project in an organized manner to higher brain centers (Deng and Rogers, 1998; Wu et al., 2000). Because PTP $\mu$ is expressed by a subset of SAC axons, it will be interesting to determine whether $\mathrm{PTP} \mu$ regulates the projection of specific subpopulations of SAC axons to the diencephalon.

РTP $\mu$ is an enzyme that catalyzes the dephosphorylation of tyrosine residues in substrate proteins. $\mathrm{PTP} \mu$-mediated adhesion may activate signals that are important for the regulation of RGC axon growth. The observed temporal-nasal gradient of $\mathrm{PTP} \mu$ expression, coupled with the reduced ability of temporal RGC neurites to grow on a $\mathrm{PTP} \mu$ substrate, indicates that $\mathrm{PTP} \mu$ signaling may restrict growth of temporal RGC axons. Other signaling molecules have been implicated in the regulation of RGC axon growth and topographic projection to the optic tectum, most notably the Eph-receptor tyrosine kinases. Eph-A3 is expressed in a nasal (low)-temporal (high) gradient in the retina, and its ephrin ligands (A2 and A5) are expressed in a reciprocal anterior-posterior gradient in the tectum (Cheng et al., 1995; Drescher et al., 1995; Nakamoto et al., 1996; Holash et al., 1997). Axons expressing the highest levels of Eph-A3 (temporal) are inhibited by tectal cells expressing higher levels of ephrin-A2 and -A5 (Nakamoto et al., 1996). However, knock-out studies of ephrin-A2 and -A5 resulted in mistargeting of both temporal and nasal axons (Feldheim et al., 2000), suggesting that multiple mechanisms are involved in regulating retinotectal pathfinding. In support of this idea, other molecules, including transcription factors and cell surface glycoproteins, have been detected in gradients within the developing retina and tectum (for review, see Thanos and Mey, 2001), but none to date have been shown to play a direct role in retinotectal pathfinding.

RPTPs have emerged recently as a new class of CAMs that play a role in axon guidance. In Drosophila, DPTP69D, DPTP99A, DLAR, and DPTP10D have been shown to act individually and in concert to regulate axon guidance in the peripheral nervous system and CNS (Desai et al., 1996; Krueger et al., 1996; Sun et al., 2000a, 2001). In addition, DPTP69D is required for lamina target specificity in the developing Drosophila visual system (Garrity et al., 1999). A subset of RPTPs, including PTP $\mu$ (BurdenGulley and Brady-Kalnay, 1999), CRYP $\alpha$ (Ledig et al., 1999a), PTPк (Drosopoulos et al., 1999), and PTP $\delta$ (Wang and Bixby, 1999), has been shown to promote neurite outgrowth in vitro, suggesting that they may also play a role in axon guidance. It is intriguing that an inhibitory role has been attributed to CRYP2/cPTPRO in the chick (Stepanek et al., 2001), HmLAR2 in the leech (Baker et al., 2000), and both DPTP10D and DPTP69D in Drosophila (Sun et al., 2000a), whereas PTP $\delta$ acts as a chemoattractant for vertebrate forebrain neurons (Sun et al., 2000b). Therefore, RPTPs can be both positive and negative regulators of axon growth, and it will be interesting to dissect their role(s) in the development of the nervous system.

The precise signals downstream of the RPTPs that are required for the regulation of neurite outgrowth are not known. For РТРк-mediated neurite outgrowth, the mitogen-activated protein kinase pathway is involved (Drosopoulos et al., 1999). For the Drosophila RPTPs, regulation of neurite outgrowth occurs via the nonreceptor tyrosine kinase Abl (Wills et al., 1999), the small G-proteins (Kaufmann et al., 1998), and the Trio family of guanine-nucleotide-exchange factors (Debant et al., 1996; for review, see Bateman and Van Vactor, 2001). РТP $\mu$-mediated signals appear to involve a receptor for activated $\mathrm{C}$ kinase (Ron et al., 1994; Mochly-Rosen and Kauvar, 1998), RACK-1 (Mourton et al., 2001). RACK-1 contains seven WD repeats and is thought to act as a scaffolding protein to recruit a number of signaling molecules into a complex (Garcia-Higuera et al., 1996). More recently, $\mathrm{PKC} \delta$ was shown to be required for $\mathrm{PTP} \mu$ dependent neurite outgrowth (Rosdahl et al., 2002). Future studies will analyze whether these signals generated by $\mathrm{PTP} \mu$ differentially regulate neurite outgrowth of nasal and temporal RGCs. 


\section{REFERENCES}

Baker MW, Rauth SJ, Macagno ER (2000) Possible role of the receptor protein tyrosine phosphatase HmLAR2 in interbranch repulsion in a leech embryonic cell. J Neurobiol 45:47-60.

Bateman J, Van Vactor D (2001) The Trio family of guanine-nucleotideexchange factors: regulators of axon guidance. J Cell Sci 114: 1973-1980.

Bixby JL, Zhang R (1990) Purified N-cadherin is a potent substrate for the rapid induction of neurite outgrowth. J Cell Biol 110:1253-1260.

Bodden K, Bixby JL (1996) Cryp-2: a receptor-type tyrosine phosphatase selectively expressed by developing vertebrate neurons. J Neurobiol 31:309-324.

Bradford M (1976) A rapid and sensitive method for the quantitation of microgram quantities of protein utilizing the principle of protein-dye binding. Anal Biochem 72:248-254.

Brady-Kalnay S (1998) Ig-superfamily phosphatases. Amsterdam: Harwood Academic.

Brady-Kalnay S, Tonks NK (1994) Identification of the homophilic binding site of the receptor protein tyrosine phosphatase $\mathrm{PTP} \mu$. J Biol Chem 269:28472-28477.

Brady-Kalnay S, Flint AJ, Tonks NK (1993) Homophilic binding of РТР $\mu$, a receptor-type protein tyrosine phosphatase, can mediate cell-cell aggregation. J Cell Biol 122:961-972.

Brady-Kalnay SM, Rimm DL, Tonks NK (1995) The receptor protein tyrosine phosphatase $\mathrm{PTP} \mu$ associates with cadherins and catenins in vivo. J Cell Biol 130:977-986.

Burden-Gulley SM, Brady-Kalnay SM (1999) РTP $\mu$ regulates N-cadherin-dependent neurite outgrowth. J Cell Biol 144:1323-1336.

Burden-Gulley SM, Lemmon V (1996) L1, N-cadherin and laminin induce distinct distribution patterns of cytoskeletal elements in growth cones. Cell Motil Cytoskeleton 35:1-23.

Burden-Gulley SM, Payne HR, Lemmon V (1995) Growth cones are actively influenced by substrate-bound adhesion molecules. J Neurosci 15:4370-4381.

Cheng HJ, Nakamoto M, Bergemann AD, Flanagan JG (1995) Complementary gradients in expression and binding of ELF-1 and Mek4 in development of the topographic retinotectal projection map. Cell 82:371-381.

Davis S, Gale N, Aldrich T, Maisonpierre P, Lhotak V, Pawson T, Goldfarb M, Yancopoulos GD (1994) Ligands for EPH-related receptor tyrosine kinases that require membrane attachment or clustering for activity. Science 266:816-819.

Debant A, Serra-Pages C, Seipel K, O'Brien S, Tang M, Park SH, Streuli M (1996) The multidomain protein Trio binds the LAR transmembrane tyrosine phosphatase, contains a protein kinase domain, and has separate rac-specific and rho-specific guanine nucleotide exchange factor domains. Proc Natl Acad Sci USA 93:5466-5471.

Deng C, Rogers LJ (1998) Organisation of the tectorotundal and SP/ IPS-rotundal projections in the chick. J Comp Neurol 394:171-185.

Desai C, Gindhart JG, Goldstein LSB, Zinn K (1996) Receptor tyrosine phosphatases are required for motor axon guidance in the Drosophila embryo. Cell 84:599-609.

Drazba J, Lemmon V (1990) The role of cell adhesion molecules in neurite outgrowth on Müller cells. Dev Biol 138:82-93.

Drescher U, Kremoser C, Handwerker C, Loschinger J, Noda M, Bonhoeffer $F$ (1995) In vitro guidance of retinal ganglion cell axons by RAGS, a $25 \mathrm{kDa}$ tectal protein related to ligands for Eph receptor tyrosine kinases. Cell 82:359-370.

Drosopoulos NE, Walsh FS, Doherty P (1999) A soluble version of the receptor-like protein tyrosine phosphatase kappa stimulates neurite outgrowth via a Grb2/MEK1-dependent signaling cascade. Mol Cell Neurosci 13:441-449.

Feldheim DA, Kim YI, Bergemann AD, Frisen J, Barbacid M, Flanagan JG (2000) Genetic analysis of ephrin-A2 and ephrin-A5 shows their requirement in multiple aspects of retinocollicular mapping. Neuron 25:563-574.

Fuchs M, Wang H, Ciossek T, Chen Z, Ullrich A (1998) Differential expression of MAM-subfamily protein tyrosine phosphatases during mouse development. Mech Dev 70:91-109.

Garcia-Higuera I, Fenoglio J, Li Y, Lewis C, Panchenko MP, Reiner O, Smith TF, Neer EJ (1996) Folding of proteins with WD-repeats: comparison of six members of the WD-repeat superfamily to the G protein beta subunit. Biochemistry 35:13985-13994.

Garrity PA, Lee CH, Salecker I, Robertson HC, Desai CJ, Zinn K, Zipursky SL (1999) Retinal axon target selection in Drosophila is regulated by a receptor protein tyrosine phosphatase. Neuron 22:707-717.

Gebbink M, van Etten I, Hateboer G, Suijkerbuijk R, Beijersbergen R, van Kessel A, Moolenaar W (1991) Cloning, expression and chromosomal localization of a new putative receptor-like protein tyrosine phosphatase. FEBS Lett 290:123-130.

Gebbink MFBG, Zondag GCM, Wubbolts RW, Beijersbergen RL, van Etten I, Moolenaar WH (1993) Cell-cell adhesion mediated by a receptor-like protein tyrosine phosphatase. J Biol Chem 268: 16101-16104.

Goodman CS (1996) Mechanisms and molecules that control growth cone guidance. Annu Rev Neurosci 19:341-377.

Halfter W, Newgreen DF, Sauter J, Schwarz U (1983) Oriented axon outgrowth from avian embryonic retinae in culture. Dev Biol 95:56-64.

Halfter W, Deiss S, Schwarz U (1985) The formation of the axonal pattern in the embryonic avian retina. J Comp Neurol 232:466-480.

Holash JA, Soans C, Chong LD, Shao J, Dixit VM, Pasquale EB (1997) Reciprocal expression of the Eph receptor Cek5 and its ligand(s) in the early retina. Dev Biol 182:256-269.

Holland SJ, Gale NW, Mbamalu G, Yancopoulos GD, Henkemeyer M, Pawson T (1996) Bidirectional signalling through the Eph-family receptor Nuk and its transmembrane ligands. Nature 383:722-725.

Inoue A, Sanes JR (1997) Lamina-specific connectivity in the brain: regulation by $\mathrm{N}$-cadherin, neurotrophins, and glycoconjugates. Science 276:1428-1431.

Johnson KG, Holt CE (2000) Expression of CRYP-alpha, LAR, PTPdelta, and PTP-rho in the developing Xenopus visual system. Mech Dev 92:291-294.

Kaufmann N, Wills Z, Van Vactor D (1998) Drosophila Rac1 controls motor axon guidance. Development 125:453-461.

Krueger NX, Van Vactor D, Wan HI, Gelbart WM, Goodman CS, Saito H (1996) The transmembrane tyrosine phosphatase DLAR controls motor axon guidance in Drosophila. Cell 84:611-622.

Lagenaur C, Lemmon V (1987) An L1-like molecule, the 8D9 antigen, is a potent substrate for neurite extension. Proc Natl Acad Sci USA 84:7753-7757.

LaVail JH, Cowan M (1971) The development of the chick optic tectum. I. Normal morphology and cytoarchitectonic development. Brain Res 28:391-419

Ledig MM, Haj F, Bixby JL, Stoker AW, Mueller BK (1999a) The receptor tyrosine phosphatase CRYPalpha promotes intraretinal axon growth. J Cell Biol 147:375-388.

Ledig MM, McKinnell IW, Mrsic-Flogel T, Wang J, Alvares C, Mason I, Bixby JL, Mueller BK, Stoker AW (1999b) Expression of receptor tyrosine phosphatases during development of the retinotectal projection of the chick. J Neurobiol 39:81-96.

Lemmon V, McCloon S (1986) The appearance of an L1-like molecule in the chick primary visual pathway. J Neurosci 6:2987-2994.

Lemmon V, Burden SM, Payne HR, Elmslie GJ, Hlavin ML (1992) Neurite growth on different substrates: permissive versus instructive influences and the role of adhesive strength. J Neurosci 12:818-826.

Lyckman AW, Jhaveri S, Feldheim DA, Vanderhaeghen P, Flanagan JG, Sur M (2001) Enhanced plasticity of retinothalamic projections in an ephrin-A2/A5 double mutant. J Neurosci 21:7684-7690.

Mey J, Thanos S (1992) Development of the visual system of the chick: a review. J Hirnforsch 33:673-702.

Miskevich F, Zhu Y, Ranscht B, Sanes JR (1998) Expression of multiple cadherins and catenins in the chick optic tectum. Mol Cell Neurosci $12: 240-255$.

Mochly-Rosen D, Kauvar LM (1998) Modulating protein kinase C signal transduction. Adv Pharmacol 44:91-145.

Mourton T, Hellberg C, Burden-Gulley S, Hinman J, Rhee A, BradyKalnay SM (2001) The PTP $\mu$ protein tyrosine phosphatase binds and recruits the scaffolding protein RACK1 to cell-cell contacts. J Biol Chem 276:14896-14901.

Nakamoto M, Cheng HJ, Friedman GC, McLaughlin T, Hansen MJ, Yoon CH, O'Leary DD, Flanagan JG (1996) Topographically specific effects of ELF-1 on retinal axon guidance in vitro and retinal axon mapping in vivo. Cell 86:755-766.

Prada C, Puga L, Perez-Mendez L, Lopez R, Ramirez G (1991) Spatial and temporal patterns of neurogenesis in the chick retina. Eur J Neurosci 3:559-569.

Rager GH (1980) Development of the retinotectal projection in the chicken. Adv Anat Embryol Cell Biol 63:1-90.

Ron D, Chen CH, Caldwell J, Jamieson L, Orr E, Mochly-Rosen D (1994) Cloning of an intracellular receptor for protein kinase C: a homolog of the beta subunit of $G$ proteins. Proc Natl Acad Sci USA 91:839-843

Rosdahl JA, Mourton TL, Brady-Kalnay SM (2002) Protein kinase C delta is required for protein tyrosine phosphatase mu-dependent neurite outgrowth. Mol Cell Neurosci 19:292-306.

Shock LP, Bare DJ, Klinz SG, Maness PF (1995) Protein tyrosine phosphatases expressed in developing brain and retinal Müller glia. Mol Brain Res 28:110-116.

Sperry RW (1963) Chemoaffinity in the orderly growth of nerve fiber patterns and connections. Proc Natl Acad Sci USA 50:703-790.

Stepanek L, Sun QL, Wang J, Wang C, Bixby JL (2001) CRYP-2/cPT$\mathrm{PRO}$ is a neurite inhibitory repulsive guidance cue for retinal neurons in vitro. J Cell Biol 154:867-878.

Stoker A, Dutta R (1998) Protein tyrosine phosphatases and neural development. BioEssays 20:463-472.

Stoker AW, Gehrig B, Newton MR, Bay BH (1995a) Comparative lo- 
calization of CRYP-alpha, a CAM-like tyrosine phosphatase, and NgCAM in the developing chick visual system. Dev Brain Res 90:129-140.

Stoker AW, Gehrig B, Haj F, Bay BH (1995b) Axonal localisation of the CAM-like tyrosine phosphatase CRYP $\alpha$ : a signaling molecule of embryonic growth cones. Development 121:1833-1844.

Sun Q, Bahri S, Schmid A, Chia W, Zinn K (2000a) Receptor tyrosine phosphatases regulate axon guidance across the midline of the Drosophila embryo. Development 127:801-812.

Sun Q, Wang J, Bookman RJ, Bixby JL (2000b) Growth cone steering by receptor tyrosine phosphatase delta defines a distinct class of guidance cue. Mol Cell Neurosci 16:686-695.

Sun Q, Schindelholz B, Knirr M, Schmid A, Zinn K (2001) Complex genetic interactions among four receptor tyrosine phosphatases regulate axon guidance in Drosophila. Mol Cell Neurosci 17:274-291.

Tessier-Lavigne M, Goodman CS (1996) The molecular biology of axon guidance. Science 274:1123-1133.

Thanos S, Bonhoeffer F (1983) Investigations on development and topographic order of retinotectal axons: anterograde and retrograde stain- ing of axons and their perikarya with rhodamine in vivo. J Comp Neurol 219:420-430.

Thanos S, Mey J (2001) Development of the visual system of the chick. II. Mechanisms of axonal guidance. Brain Res Brain Res Rev 35:205-245.

Vielmetter J, Stolze B, Bonhoeffer F, Stuermer CAO (1990) In vitro assay to test differential substrate affinities of growing axons and migratory cells. Exp Brain Res 81:283-287.

Wang J, Bixby JL (1999) Receptor tyrosine phosphatase-delta is a homophilic, neurite-promoting cell adhesion molecule for CNS neurons. Mol Cell Neurosci 14:370-384.

Wills Z, Bateman J, Korey CA, Comer A, Van Vactor D (1999) The tyrosine kinase Abl and its substrate enabled collaborate with the receptor phosphatase Dlar to control motor axon guidance. Neuron 22:301-312.

Wu CC, Russell RM, Karten HJ (2000) Ontogeny of the tectorotundal pathway in chicks (Gallus gallus): birthdating and pathway tracing study. J Comp Neurol 417:115-132. 